NBER WORKING PAPER SERIES

SCHOOLING AND HEALTH. THE CIGAREITE CONNECTION

Phillip Farrell

Victor R. Fuchs

Working Paper No. $7 \underline{68}$

NATIONAL BUREAU OF ECONOMIC RESEARCH

1050 Massachusetts Avenue

Cambridge MA 02138

September 1981

This research was supported by a grant from the Robert Wood Johnson Foundation. The Stanford University Heart Disease Prevention Program generously provided the survey data that made this study possible. Helpful comments on an earlier draft were provided by Jeffrey Harris, Michael Grossman, Eugene Lewit, and Wm. Byron Brown. The research reported here is part of the NBER's research program in Health Economics. Any opinions expressed are those of the authors and not those of the National Bureau of Economic Research. 


\section{Schooling and Health: The Cigarette Connection}

\section{ABSTRACT}

Numerous studies by economists during the past decade have revealed a large, statistically significant correlation between health and years of schooling after controlling for differences in income and other variables. Cigarette smoking is a likely intervening variable because of the strong effect of smoking on morbidity and mortality, and because there is a strong negative correlation between smoking and years of schooling--at least at high school levels and above. This paper tests the hypothesis that schooling causes differences in smoking behavior. We use retrospective smoking histories of 1,183 white, non-Hispanic men and women who had completed 12 to 18 years of schooling. The data were collected in 1979 by the stanford University Heart Disease Prevention Program from randomly selected households in four small California cities.

The most striking result is that the negative relation between schooling and smoking observed at age 24 is accounted for by differences in smoking behavior present at age 17 , when all subjects were still in approximately the same grade. We conclude that additional years of schooling cannot be the cause of differential smoking behavior; one or more "third variables" must cause changes in both smoking and schooling. Analysis of smoking by cohort reveals that the schooling-smoking correlation developed only after the health consequences of smoking became widely known; it has remained strong even in the most recent cohorts. This implies that the mechanism behind the schooling-smoking correlation may also give rise to the schooling-health correlation.

Phillip Farrell and

Victor R. Fuchs

both at

National Bureau of Economic Research 204 Junipero Serra Boulevard

Stanford, California 94305

$415 / 326-7160$ 


\title{
SCHOOLING AND HEALTH: THE CIGARETTE CONNECTION
}

\author{
Phillip Farrell and Victor R. Fuchs
}

One of the strongest generalizations to emerge from empirical research on health in the United States is a positive correlation between years of schooling and health status. At one time this relationship was viewed as a "class" or "socioeconomic status" effect and was thought to be significantly influenced by a positive relation between schooling and income and a positive effect of income on health (A. Antonovsky, 1967). Numerous studies by economists during the past decade, however, have revealed a large, statistically significant relationship between health and years of schooling after controlling for differences in income. $1 /$

In a detailed exploration of the subject Michael Grossman (1975) showed that this relationship was strong even among a population of middleaged white men, all of whom had at least completed high school. He also showed that the relationship persisted after controlling for a large number of family background variables, I.Q., and health status in high school. Grossman has hypothesized that the additional years of schooling make an individual a more efficient producer of health. This greater efficiency may express itself through more judicious use of medical care or through more knowledgeable choices about diet, exercise, cigarette smoking, and other health-affecting activities.

Systematic differences in "life style" by years of schooling are readily discernible (controlling for income), but such differences are consistent with schooling-induced shifts in preferences as well as with the augmented efficiency hypothesis. One attempt to test for schooling 
effects in the use of, and outcomes from, in-hospital surgical operations had essentially negarive results (Louis Garrison, 1981). Years of schooling was not systematically related to the stage of the disease at the time of surgery, qualifications of the surgeon, length of hospital stay, or even outcome of the surgery (controlling for the initially better general health of those with more schooling).

Cigarette smoking has been regarded as a likely intervening variable between schooling and health for two reasons. First, the relationship between cigarette smoking and health is very strong. Among males with life insurance the gross difference in life expectancy at age 35 between nonsmokers and those who smoke a pack a day is approximately six years (Jeffrey Harris, 1981). Even within a relatively homogeneous population such as regular participants in the Kaiser-Permanente Multiphasic Health checkups, the age-sex-race-adjusted death rate for cigarette smokers is double that of nonsmokers (G. D. Friedman et al., 1981). Second, there is a strong negative relationship between cigarette smoking and years of schooling, at least at high school levels or above. In a 1975 national probability survey the proportion of high school graduates who smoked was more than $50 \%$ higher than that of college graduates (DHEW, 1976).

The reasons for the schooling-smoking relationship are not well understood. One class of explanations asserts that schooling has a direct effect on smoking behavior. Additional schooling may increase knowledge about the harmful effects of smoking, it may change preferences, or $1 t$ may increase the individual's ability to develop strategies of self-control (Richard Thaler and H. M. Shefrin, 1981). A second class of explanations denies any causal role for years of schooling and asserts that the correlation 
is attributable to one or more "third variables" that affect both schooling and smoking behavior.

The purpose of this paper is to test alternative explanations of the schooling-smoking relation. Such tests may contribute to a better understanding of smoking behavior and of the larger question of the correlation between schooling and health. Our research strategy is to examine the smoking behavior of different cohorts of men and women before and after they have completed their formal schooling. Pre- and post-schooling observations can shed light on whether additional years of schooling changes behavior. Analyses of starting behavior by cohorts and quitting behavior in different time periods can reveal how the schoolingsmoking relation was affected by the spread of information about the adverse effects of cigarettes on health. 
Data and Methods

The sample. The data used in this paper are drawn from 2,504

personal interviews conducted in the fall of 1979 by the Stanford Heart Disease Prevention Program (SHDPP) among residents aged 12 to 75 years in randomly selected households in four small California cities: Modesto, Monterey, Salinas, and San Luis obispo. All cities are located in predominantly agricultural areas; their populations range between 30,000 and 130,000 (in 1975). The interviews were taken as part of a health education experiment designed to test the effectiveness of techniques for altering smoking, exercise, and dietary behaviors in order to reduce risk of heart disease (Nathan Maccoby and Douglas Solomon, 1981).

Table 1 shows that the relations between schooling and health and schooling and smoking status in this sample are similar to those reported in national surveys. Health status as measured by days of norma $\perp$ activity limited by illness improves systematically with schooling. Other health indicators (not shown) such as health care utilization or personal satisfaction with health also show systematic improvement with increased schooling. The proportion smoking cigarettes on a daily basis declines with years of schooling (except for increases at the very lowest levels of schooling, not separately shown). Men are more likely to smoke than women, and the proportion smoking is higher at age 24 than at age 17 .

For the regression analyses that follow a subset of 1,183 survey respondents was selected consisting of white, non-Hispanic men and women who were not students at the time of the survey, had completed 12 to 18 years of schooling, and who were at least 24 years old; $45 \%$ were men and $55 \%$ women. Nonwhites and Hispanics (about $17 \%$ of the survey respondents) 
Table 1. Age-adjusted- mean health and smoking status, by years of completed schooling and sex: white men and women aged 24 to 75 years, 1979 survey of the Stanford Heart Disease Prevention Program.

\begin{tabular}{llllll}
\hline \hline Years of & Number of & Days illness & & \multicolumn{2}{c}{ Proportion smoking on a daily basis } \\
\cline { 4 - 8 } schooling & observations & limitation & & In 1979 At age 17 At age 24 Ever \\
\hline
\end{tabular}

M E N

$\begin{array}{rrrrrrr}\leq 11 & 81 & 15.9 & .508 & .652 & .818 & .924 \\ 12 & 165 & 15.0 & .477 & .461 & .707 & .752 \\ 13 \text { to } 15 & 183 & 10.7 & .381 & .292 & .583 & .689 \\ \geq 16 & 232 & 3.2 & .193 & .178 & .393 & .535\end{array}$

WOMEN

$\begin{array}{rrrrrrr}\leq 11 & 128 & 29.4 & .470 & .380 & .517 & .616 \\ 12 & 268 & 16.2 & .377 & .226 & .476 & .618 \\ 13 \text { to } 15 & 210 & 10.2 & .313 & .176 & .422 & .537 \\ \geq 16 & 190 & 9.7 & .205 & .087 & .293 & .391\end{array}$

a/ Adjusted by the direct method using the following age categories of approximately equal cell size: $24-29,30-39,40-49,50-59$, and 60-75.

b/Number of days during past year when normal activities were limited by illness. 
were excluded because the sample size was inadequate to explore interactions among ethnicity, schooling, and smoking. Persons still in school or under age 24 were excluded in order to focus on those who have had ample opportunity to reveal their decisions about schooling and initiation of smoking. Over $90 \%$ of the ever regular smokers in the SHDPP survey began smoking by age 24 . Using a higher cut-off age (to capture a higher percentage of all possible smokers) would remove from the study too many of the younger cohorts who have been most exposed to information about the health consequences of smoking .

To test the hypothesis of a causal relationship between schooling and smoking, we need to observe a sample of individuals both before and after they had completed differing amounts of schooling. Assuming uninterrupted attendance in school from age 6 onward, those with more than 18 years of schooling were excluded so that everyone in our sample (including those just age 24 in 1979) could be observed after the completion of schooling. Persons with less than 12 years of schooling were excluded so that the entire sample would still be in school at age 17 , when nearly half of the ever regular smokers in this sample had begun smoking. To include. persons with fewer years of schooling and still achieve the objective of observing the entire sample at a common age when all were still in school, a younger age would have to be selected when there was not yet much smoking activity.

With this sample we can study the effects of additional years of schooling (beyond 12) on smoking behavior; we cannot explicitly investigate the effects of differences in the quality or type of schooling, although the effects should be similar since differences in quality of schooling are a particular dimension of quantity of education, ceteris paribus. We 
will look at the relation between schooling (ultimately completed) and the probability of smoking at ages 17 and 24; we will also examine the relation between schooling and the probability of continuing to smoke, conditional on having been a regular smoker.

The variables. Respondents to the SHDPP 1979 survey were asked if they had ever smoked cigarettes on a daily basis. Those who responded affirmatively are classified as "ever regular smokers." Ever regular smokers were also asked at what age they began smoking and whether they had smoked in the past week. Those who had smoked in the past week are considered current regular smokers; those who had not are considered former regular smokers. Former regular smokers were asked how long ago they quit. The answers to these questions were used to construct retrospective histories of smoking status. $\underline{2}$ I

Education was recorded in the SHDPP 1979 survey as number of years of formal schooling completed. Education was tried in the analyses in both continuous and categorical forms with similar results. Family background characteristics such as cultural traditions (including religion), income, and whether the parents smoked are possibly important influences on whether a person begins to smoke. Unfortunately, the only such background characteristic included in the 1979 SHDPP survey was father's years of completed schooling. Approximately $17 \%$ of the white survey respondents did not give father's schooling; the median years of completed father's schooling for their ten-year age cohort was assigned. $3 /$ Although generally not statistically significant in either continuous or categorical forms, father's schooling was retained in the final regression. The absence of other background variables may be less of a problem in this relatively homogeneous sample than in a national sample. 
Cohorts were defined according to historical periods of possibly different smoking behavior. The critical years were believed to be entry into World War 2 (1942), the first appearance in the popular press of articles linking smoking to lung cancer ${ }^{4 /}$ (c. 1953), and the publication of the first Surgeon General's Report on Smoking and Health (DHEW, 1964). Survey respondents were assigned to the cohort that included the calendar year when they were 17 years of age. The four cohorts defined by these three important years were roughly equal in size in these data; further sub-divisions of each cohort were used in some analyses.

Possible bias in variables. Potential systematic bias in the measurement of smoking status is an important concern, especially if bias is correlated with education. The most obvious potential source of bias when using survey results is the possibility that respondents lie about their smoking status or history in order to avoid perceived social stigma or disapproval. Fortunately, tests for the presence of smoking by-products carbon monoxide in expired air and thiocyanate in blood samples collected by the SHDPP as part of their survey establish the veracity of self-reported current smoking behavior, and by extension, previous smoking behavior (since the motivation to lie--social stigma--would be less strong for previous smoking than current smoking.

All of the female self-reported nonsmokers (including former smokers) and $97.5 \%$ of the male ones had levels of smoking by-products well below "threshold levels" used to classify typical smokers (8 ppm CO and 100 micromoles/liter thiocyanate; see Vogt et al., 1977). Furthermore, for selfreported nonsmokers mean levels of these by-products (and thus the probability of lying) decreased with increased years of schooling, though only the differences in co levels were statistically significant. $5 /$ If present at all, 
systematic bias due to "lying" is thus very minor and works in the direction of reducing, not increasing, the observed strength of the schooling-smoking relationship.

Another potential source of bias is differential survivorship of smokers and nonsmokers. The direction and size of bias depends upon the absolute difference in mortality, the true proportion who were smokers at different levels of schooling, and possible effects on death rates of interactions between smoking and education. We have attempted to estimate the potential bias assuming mortality rates for smokers that were double those of nonsmokers, and concluded that even for our oldest cohort the effect is small unless the interaction between smoking and education was very large. $6 /$ Most important of all, considering the purposes of this paper, the effect on the comparison between the schooling-smoking relationship at ages 17 and 24 is regligitle.

Estimation. Because of the dichotomous nature of the smoking state variables, the binary logistic model was used to estimate regressions of smoking on schooling. In this model the probability of smoking, $P$, is assumed to be related to the independent variables by

$$
P=\frac{1}{1+e^{-B X}}
$$

where $X$ is the vector of independent variables and $B$ is the vector of estimated coefficients. All estimations were done with the maximum likelthood iterative procedure "LOGIST" of the Statistical Analysis System version $79.4 \mathrm{~b}$, on an IBM $370 / 3033$ processor. Observed proportions smoking corresponded closely to proportions predicted from the regressions, indicating the appropriateness of the functional form. 


\section{Results}

Table 2 reports the results of maximum likelihood logit regressions in which the probability of smoking is a function of years of own schooling, years of father's schooling, cohort and interactions between cohort and own schooling. Identical regressions were estimated for the probability of smoking at age 17 and age 24 with schooling measured in both cases as the number of years the individual would eventually complete (by 1979). This specification permits a test of whether the schooling-smoking relationship observed in this sample was established before or after the additional years of schooling were obtained. The schooling by cohort interactions allow a test of whether the effect was associated with the news of adverse health effects from smoking.

The most striking result is that the negative relation between schooling and smoking is generally as strong at age 17 as at age 24 for all cohorts; for women, the relationship is stronger at age 17 than at age 24 for the two most recent cohorts. At age 17, however, the individuals were all still in the same school grade (approximately). Thus the relative differences in the probability of smoking that are observed at age 24 between persons with differing years of schooling are already present at age 17, before the schooling is obtained. The additional schooling cannot be the cause of the differential smoking behavior.

The second important result is that the differences in smoking by years of schooling appear to be motivated, at least in part, by health concerns. This can be seen in the variation in the schooling coefficients by cohort, which shows how the schooling-smoking relation has changed over time. This variation is important because before 1953 there was little 
public discussion linking cigarettes to bad health, and before 1964 there was little explicit public anti-smoking policy.

The regression results in Table 2 show that schooling has a sharply different relation to smoking in the periods before and after health consequences of smoking became a major public concern. The total schooling coefficients 7 for the two pre-1953, cohorts are small for all age/sex combinations, and none are significantly different from zero ( $p>.10$ for all) or from each other. For women, the 1953-1964 cohort coefficients appear to still show a statistically insignificant relation between schooling and smoking (although, see the results below using finer cohort classifications). Beginning with the 1953-64 cohort for men, and continuing through the 1964-72 cohort for both men and women, the total schooling coefficients at both ages became strongly and sharply negative; they are statistically different from the pre-1953 coefficients at $p<.05$ and different from zero at $p<.01$ (based on the standard errors of the total coefficients, not shown in the table).

The coefficients for father's schooling in Table 2 are small and statistically insignificant. Even if own schooling is left out of the regression or interactions between father's schooling and cohort are added, the father's schooling coefficient remains weak. Father's schooling may perform poorly in these regressions because of correlation with several potentially conflicting influences on smoking, such as social class and family income. For instance, father's schooling might be positively correlated with smoking among women in older cohorts because social disapproval of smoking by women was stronger for the "lower class" (Jeffrey Harris, 1980). Father's schooling could be correlated with decreased probability of smoking, 


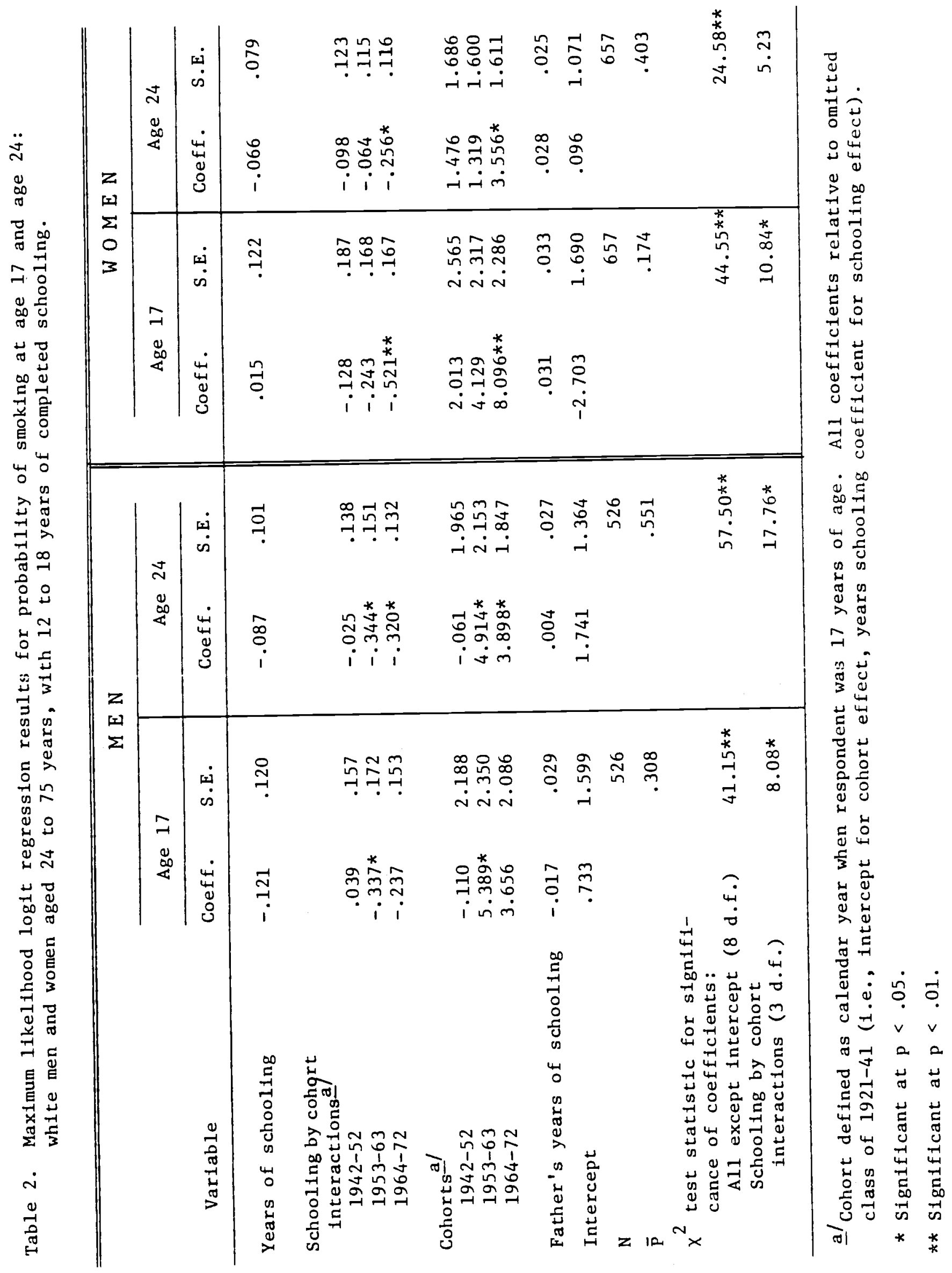


at least during the era of health concerns about smoking, through a negative relation between father's own smoking and schooling coupled with a positive influence of parental smoking on teenage smoking. Finally, father's schooling is undoubtedly positively correlated with family income. If income elasticity of demand for cigarettes has declined over time, father's schooling may have positively influenced smoking through an income effect among older cohorts but not among younger cohorts.

The intercept and simple cohort coefficients in Table 2 show the partial effect of cohort, holding the effect of interactions between schooling and cohort at zero. To obtain the partial difference between two cohorts holding schooling constant at some non-zero level, one must sum the difference between the simple cohort dummy coefficients and the difference between the schooling by cohort interaction coefficients (evaluated at the specified level of schooling). Evaluating the inter-cohort effects with schooling held constant at the mean value (rather than zero) produces a set of cohort difference coefficients that are considerably reduced in magnitude and different in pattern from the simple cohort dummy variable coefficients shown in Table 2 .

At mean schooling levels, the partial effect of cohort for men is increased smoking in successively younger cohorts up to the 1953-63 cohort for both ages (except for a dip at age 24 in the 1942-52 cohort), followed by a sharp decline in smoking in the 1964-72 cohort. For women, smoking increases in successive cohorts right through the 1964-72 cohort at age 17; at age 24, smoking increases through the 1953-63 cohort and then drops sharply in the 1964-72 cohort. None of these cohort-to-cohort changes are statistically significant (at $p<.05$ ), however, except the decrease in smoking among 24-year-old men in the 1964-72 cohort. 
Another way to view the difference in the schooling-smoking relation by cohort, age, and sex is to examine the predicted probabilities of smoking implied by the regression results. Table 3 shows those predictions for the end values and midpoint of years of schooling, for each cohort/age/sex combination. These predicted probabilities clearly show the dramatic change in the schooling-smoking relation between the pre- and post-"health concern" cohorts. The strong negative relation between schooling and smoking came about primarily from decreases in smoking by the highly educated; smoking probabilities for those with only 12 years of schooling are generally as high or higher in the post-"health concern" cohorts as in the pre-"health concern" cohorts. Table 3 also reaffirms that the schooling-smoking relationship observed at age 24 , after schooling was completed, could be accounted for by equally strong differences in smoking probabilities among the same individuals at age 17 , before they had obtained differential amounts of schooling.

In order to obtain a more detailed view of the timing of changes in the schooling-smoking relation the four cohorts in the regression of Table 2 were further divided into nine cohorts of approximately equal size within each sex. Maximum likelihood logit regressions were estimated for each cohort within each sex separately for the probability of smoking at ages 17 and 24 versus own schooling and intercept (father's schooling was omitted because of its insignificant coefficient in previous regressions). The schooling coefficients are plotted on an inverted scale versus the cohort mean year. (See Figure 1.)

The schooling coefficients are estimated less precisely because of smaller sample sizes (standard errors range from .10 to .26, with a mean of .16). Nevertheless, Figure 1 confirms Table 2 and shows even more clearly 
Table 3. Predicted probability of smoking at ages 17 and 24 , by sex, cohort, and years of completed schooling:- white men and women aged $24-75$ years, with 12 to 18 years of completed schooling.

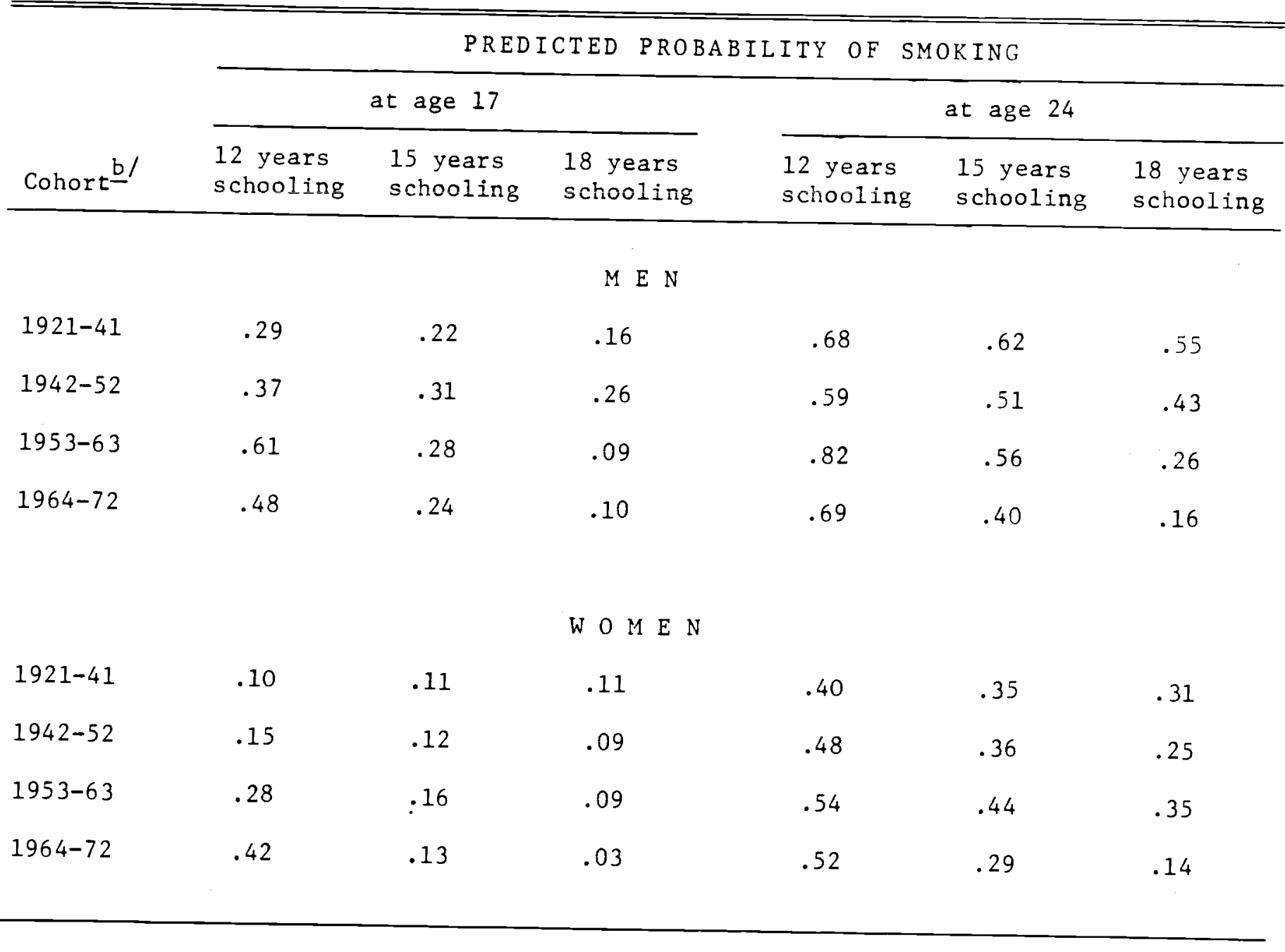

a / Based on maximum likelihood logit regressions of probability of smoking reported in Table 2. Probabilities are evaluated at mean father's schooling. b/Defined by calendar year when age 17 . 


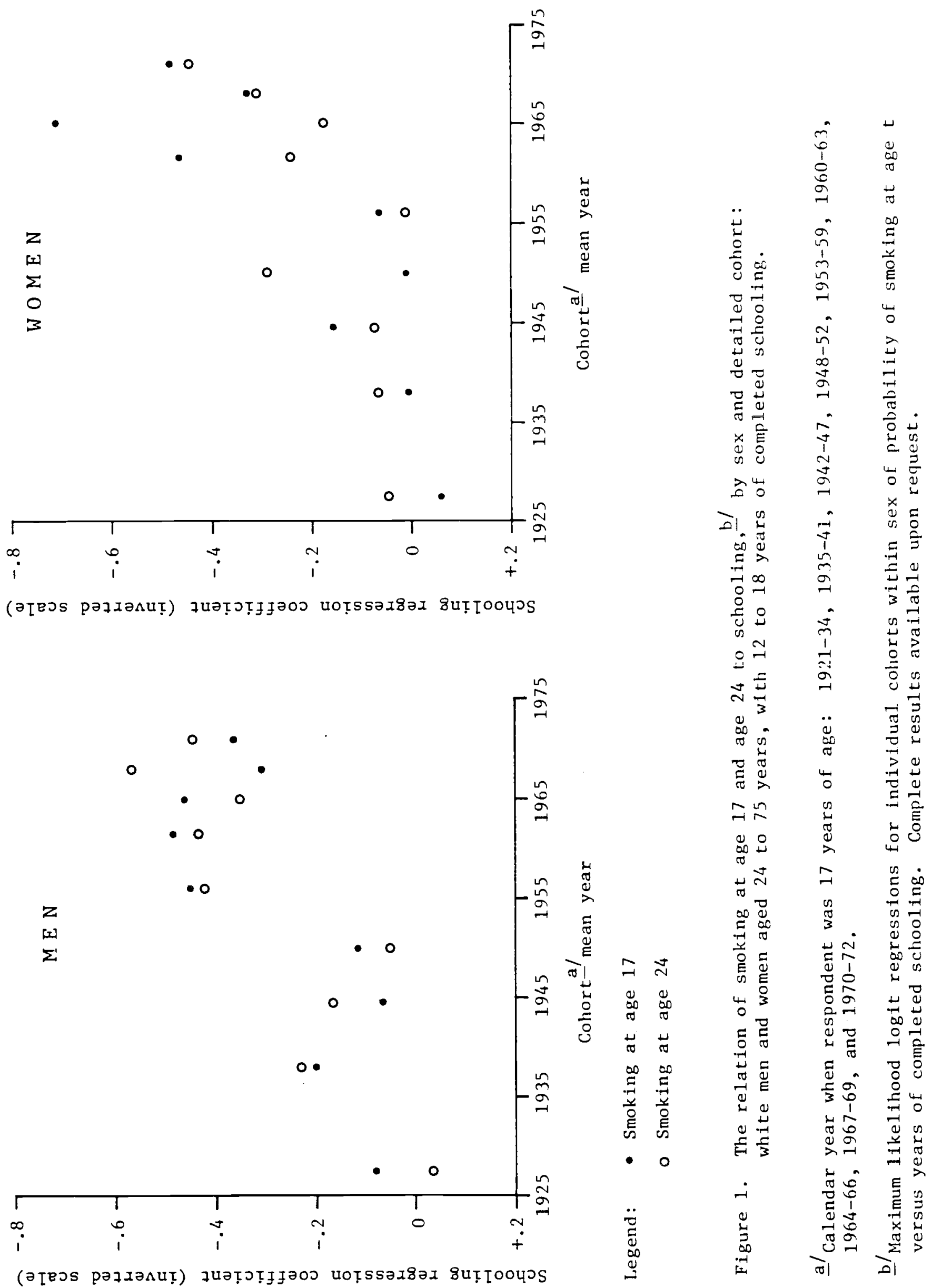


the dramatic change in the schooling-smoking relation that occurred after knowledge of adverse health effects of smoking became widespread. For men the strong schooling-smoking relation begins with the 1953-59 cohort; for women it begins with the 1960-63 cohort. The more detailed cohort analysis also confirms the finding that the schooling-smoking relation is as strong at age 17 as at age 24 .

Additional support for the conclusion that the schooling-smoking relation only developed after the health effects of smoking became widely publicized comes from regressions of quitting behavior (see Table 4). It is only in the 1964-79 period that the probability of smoking at the end of the period (conditional on having smoked someting during the period) was significantly related to years of schooling (for men).

\section{Discussion}

The data examined in this paper reject the hypothesis that additional years of schooling play a significant causal role in the schooling-smoking correlation. $8 /$ There are apparently one or more "third variables" that affect both smoking and years of schooling. These data do, however, support the hypothesis that the schooling-smoking relation, and by implication, the effect of any underlying "third variable," is related to considerations of health consequences of smoking.

What is the third variable that leads to differences in both schooling and smoking? The data reject the view that differences in "social class" are the underlying cause. First, the effect of father's schooling is very weak and not statistically significant even in regressions which omit the individual's own schooling. Second, "class" effects should presumably have 
Table 4. Maximum likelihood logit regressions of whether still smoking at end of period, conditional on having smoked sometime during the period: white men and women ages $24-75$, with $12-18$ completed years of schooling.

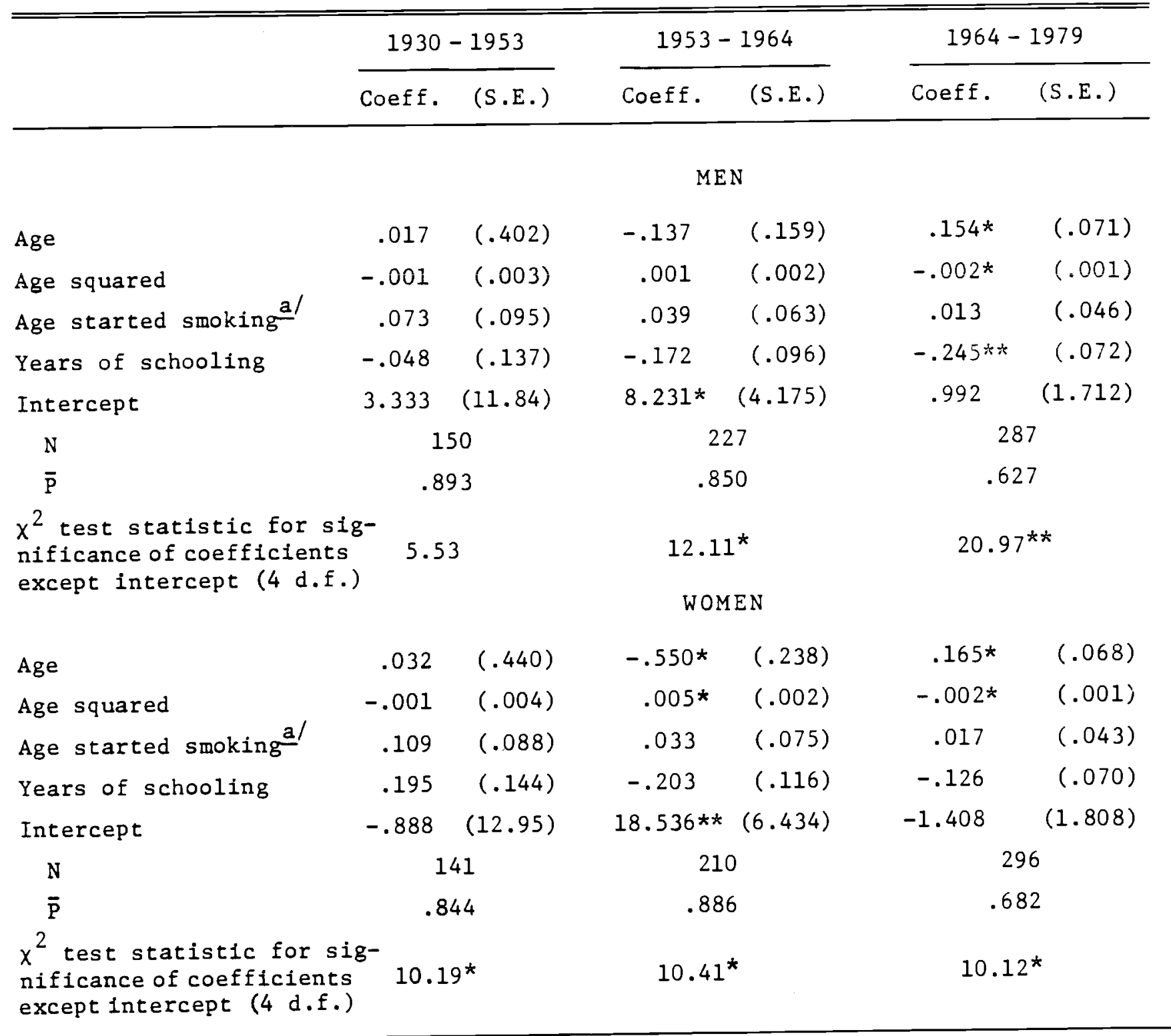

a/ Truncated at 15 and 25.

* significant at $\mathrm{p}<.05$.

** significant at $\mathrm{p}<.01$. 
been present for the older cohorts as well as the more recent ones, but no significant relation between schooling and smoking emerges until after 1953 for men and after 1960 for women.

Mental ability is another possible third variable. Those individuals who complete additional schooling are presumably more intelligent. Differences in smoking incidence among high school students have also been correlated with differences in academic performance, which itself is a correlate of ability (Barry Borland and Joseph Rudolph, 1975). Thus, even though all our sample have the same number of years of schooling at age 17 , those of greater mental ability may more rapidly absorb and act upon information about the harmful effects of smoking, as well as obtain more additional schooling. If the schooling-smoking correlation was primarily due to superior mental ability, however, one might expect that it would become weaker over time as knowledge about the harmful effects of smoking became more widely diffused. The analysis by cohort provides no evidence of such weakening over time. Fuchs (forthcoming, 1982) suggests that both schooling and smoking behavior are related to individual differences in time discount, i.e., willingness and ability to incur current costs for future benefits. Schooling has long been recognized as a form of investment; decisions about cigarette smoking have a similar character. Assuming imperfect capital markets, differences in time discount could explain the observed correlation between schooling and smoking. The data in this study are consistent with this hypothesis, but cannot test it.

Cigarette smoking is undoubtedly an important intervening variable in the correlation between schooling and health. If, as this study suggests, additional years of schooling is not causally related to smoking, identification of the "third variable" that affects both may provide a key to understanding the schooling-health relationship. 


\section{FOOTNOTES}

1. For example, see: Richard Auster et al., 1969; Michael Grossman, 1972; Joseph P. Newhouse and L. J. Friedlander, 1980; and Paul Taubman and Sherwin Rosen, forthcoming 1982.

2. Spells of nonsmoking by current regular smokers were ignored, since their duration and timing were not recorded in the survey. For our purposes the error thus introduced in determination of smoking status at 17 or 24 is probably not significant.

3. Regressions were also tried excluding those missing father's years of completed schooling. Results were the same as the full sample with median values assigned to missing observations.

4. For example, Consumer's Union, 1954; C. W. Lieb, 1953; L. M. Miller and J. Monahan, 1954; and R. Norr, 1952.

5. In our subset of whites aged $24-75$, the mean levels of expired air CO (ppm) and blood thiocyanate (micro-moles/liter) for self-reported smokers and nonsmokers varied by years of schooling as follows (standard errors of the means in parentheses):

$\frac{\text { Smokers }}{\text { Men }} \mathrm{CO}^{\text {Women }}$

12 years schooling

$16+$ years schooling

$\begin{array}{ll}28.7 & 25.6 \\ (1.95) & (1.86)\end{array}$

$26.0 \quad 17.9$

Thiocyanate

$\begin{array}{ccc}12 \text { years schooling } & \begin{array}{c}154.1 \\ (6.26)\end{array} & \begin{array}{c}166.3 \\ (5.68)\end{array} \\ & & 155.1 \\ 16+\text { years schooling } & 155.2 \\ & (8.83) & (11.32)\end{array}$

\begin{tabular}{|c|c|}
\hline \multicolumn{2}{|c|}{ Nonsmokers } \\
\hline Men & Women \\
\hline \multicolumn{2}{|c|}{$\mathrm{CO}$} \\
\hline $\begin{array}{l}6.26 \\
(.62)\end{array}$ & $\begin{array}{l}4.08 \\
(.12)\end{array}$ \\
\hline $\begin{array}{l}4.79 \\
(.24)\end{array}$ & $\begin{array}{l}3.80 \\
(.12)\end{array}$ \\
\hline
\end{tabular}

Thiocyanate

$\begin{array}{ll}65.6 & 48.9 \\ (4.04) & (1.57 \\ 62.3 & 49.3 \\ (2.57) & (1.73)\end{array}$


6. The ratio of the probability of smoking for 12 th versus 18 th graders changed by about $10 \%$ after removing effects of survivorship bias, assuming no interactions. Details of the calculation available upon request.

7. The total schooling coefficient for any cohort is obtained by adding the cohort interaction effect in Table 2 to the base schooling coefficient; differences in the effect of schooling between cohorts are simply the differences in the cohort interaction coefficients (or the interaction coefficients themselves for differences from the omitted 1921-41 cohort).

8. This paper does not explicitly address the possibility that differences in quality of schooling prior to the 12 th grade could be the cause of the observed differences in smoking behavior at age 17. Differences in quality, however, are similar to additional years of schooling because both reflect differences in the quantity of education inputs into the individual. We find no causal relationship between education inputs after the 12 th grade (in the form of additional years of schooling) and smoking. To assert a strong causal role for education inputs up to the 12 th grade (in the form of "quality" differences) would then require that causality suddenly cease after the 12 th grade. It stretches plausibility to suppose that schooling can increase knowledge, change preferences, increase ability for self-control, or otherwise exert strong influence over smoking behavior until the 12 th grade and not at all thereafter. 


\section{REFERENCES}

A. Antonovsky, "Social Class, Life Expectation and Overall Mortality," Milbank Memorial Fund Quarterly, January 1967, 31-37.

Richard Auster, Irving Leveson, Deborah Sarachek, "The Production of Health, an Exploratory Study," J. Human Resources, Fal1 1969, 4, 412-36.

Barry L. Borland and Joseph P. Rudolph, "Relative Effects of Low Socioeconomic Status, Parental Smoking and Poor Scholastic Performance on Smoking Among High School Students," Social Science and Medicine, January $1975, \underline{9}, 27-30$.

Consumer's Union, "Cigarette Smoking and Lung Cancer," Consumer Reports, Feb. $1954, \underline{19}, 54-92$.

Gary D. Friedman, Diana B. Petitti, Richard D. Bawol, and A. B. Siegelaub, "Mortality in Cigarette Smokers and Quitters," New England J. of Medicine, June 4, 1981, 304(23), 1407-10.

Victor R. Fuchs, "Time Preference and Health: An Exploratory Study," in Victor R. Fuchs (ed.), Economic Aspects of Health, proceedings of a conference, Chicago, 1982 forthcoming.

Louis P. Garrison, "Studies in the Economics of Surgery," Ph.D. dissertation, Stanford University, 1981.

Michael Grossman, "On the Concept of Health Capital and the Demand for Health," J. Polit. Econ., March/April 1972, 80, 223-55. , "The Correlation between Health and Schooling," in Nestor E. Terleckyj (ed.), Household Production and Consumption, New York, 1975. Jeffrey E. Harris, "Cigarette Smoking in the United States, 1950-1978," in USDHEW, Public Health Service, Smoking and Health, a Report of the Surgeon General (Appendix), DHEW Publ. No. (PHS)79-50066, Washington, 1979 . 
, "Patterns of Cigarette Smoking," in USDHHS, Public Health

Service, The Health Consequences of Smoking for Women, a Report

of the Surgeon General (Part I), Washington, 1980.

, "On the Mortality Risk of Cigarette Smoking," presented at the

International Workshop on the Analysis of Actual versus Perceived

Risks, Washington, D.C., June 1-3, 1981.

C. W. Lieb, "Can the Poisons in Cigarettes be Avoided?" Reader's Digest, December 1953, 63, 45-47.

Nathan Maccoby and Douglas S. Solomon, "Health Disease Prevention: MultiCommunity Studies," in R. E. Rice and W. J. Paisley (eds.), Public Communication Campaigns, Beverly Hills, 1981.

L. M. Miller and J. Monahan, "The Facts Behind the Cigarette Controversy," Reader's Digest, July 1954, 65, 1-6.

Joseph P. Newhouse and L. J. Friedlander, "The Relationship between Medical

Resources and Measures of Health: Some Additional Evidence,"

J. Human Resources, Spring 1980, 15, 200-18.

R. Norr, "Cancer by the Carton," Reader's Digest, December 1952, 61, 7-8.

Paul Taubman and Sherwin Rosen, "Healthiness, Education and Marital Status,"

in Victor R. Fuchs (ed.), Economic Aspects of Health, Chicago, 1982

forthcoming.

Richard A. Thaler and H. M. Shefrin, "An Economic Theory of Self Control," J. Polit. Econ., April 1981, 89, 392-406.

U.S. Department of Health, Education, and Welfare; National Clearinghouse for Smoking and Health, Adult Use of Tobacco-1975, Washington, 1976. ; Public Health Service, Smoking and Health, Report of the Advisory Committee to the Surgeon General, PHS Publication No. 1103, Washington, 1964. 
T. M. Vogt, S. Selvin, G. Widdowson, and S. B. Hulley, "Expired Air Carbon Monoxide and Serum Thiocyanate as Objective Measures of Cigarette Exposure," Amer. J. Public Health, June 1977, 67, 545-49. 